\title{
PHOTOCHEMICAL SOLAR ENERGY CONVERSION UTILIZING SEMICONDUCTORS LOCALIZED IN MEMBRANE-MIMETIC SYSTEMS
}

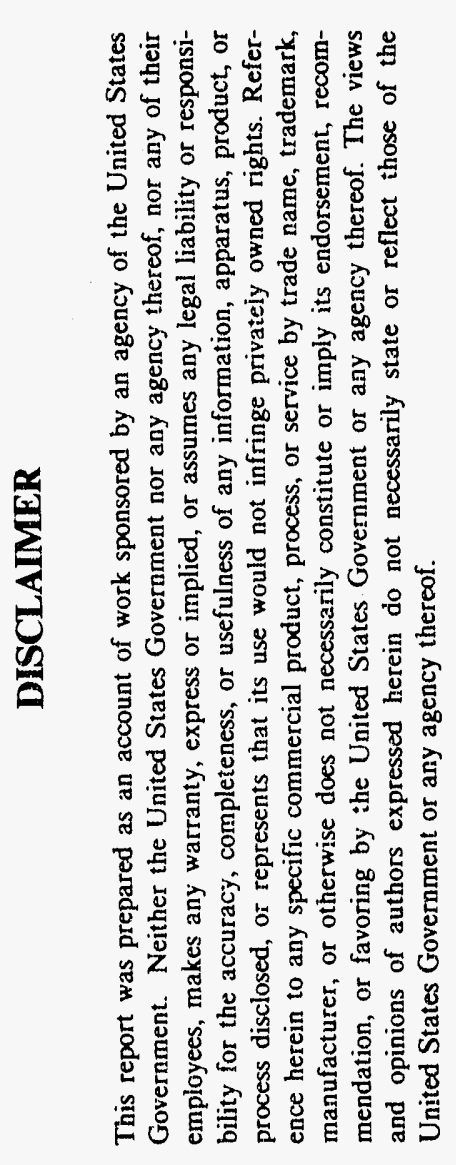

Performance Report

DOE/ER/13506--37

April 1, 1989, to August 31, 1991

Janos H. Fendler

Department of Chemistry

Syracuse University

Syracuse, New York 13244-4100

Prepared for the Department of Energy

Under Grant Number DE-FG02-86ER13506

August 31, 1991

\section{MASTER}




\section{SUMMARY}

Extending the frontiers of colloidal photochemistry and colloidal electrochemistry to solar photochemistry research had been the main objective of the research proposed to the Office of Basic Energy Sciences for the period of April 1, 1989, to March 31, 1992. More specific objectives of this proposal included the examination of semiconductor-particlemediated photoelectron transfer and photoelectric effects in different membrane mimetic systems. Emphasis had been placed on developing bilayer lipid membranes (BLMs) and Langmuir-Blodgett (LB) films as new membrane-mimetic systems, as well as on the characterization and utilization of these systems. The major objectives of the proposed research have been accomplished. Work completed under this grant from April 1, 1989, to August 31,1991 , has led to 18 publications and 22 oral presentations at national and international meetings and institutions. A brief narrative summary of the published work is provided in the following pages, along with reprints of published papers and abstracts of manuscripts which are in press or have been submitted for publication. 


\section{SCIENTIFIC PROGRESS}

\section{A. Semiconductor Particles in Vesicles}

Surfactant vesicles have continued to be utilized for the compartmentalization of the components of the artificial photosynthetic apparatus. The relative simplicity of surfactant vesicles rendered them to be useful for developing methodologies for the more complex bilayer lipid membranes (BLMs) and Langmuir-Blodgett (LB) films.

We have investigated dihexadecyl phosphate (DHP), vesicle-stabilized, in situgenerated, mixed CdS and ZnS semiconductor particles. Depending on the experimental conditions selected, either colloidal mixed crystals of $\mathrm{Zn}_{\mathrm{x}} \mathrm{Cd}_{1-\mathrm{x}} \mathrm{S}$ or $\mathrm{ZnS}$-coated $\mathrm{CdS}$ or CdS-coated $\mathrm{ZnS}$ particles were formed. Investigations of these vesicle-incorporated semiconductor particles by absorption and fluorescence spectroscopy, as well as by X-ray diffraction and laser-flash photolysis, revealed subtle and controllable changes in their bandgaps, reduction potentials, and photoelectron transfer efficiencies. Differences in the composition of the surfactant-vesicle-incorporated semiconductor particles have also manifested in different efficiencies of hydrogen generation in the presence of benzyl alcohol as a sacrificial electron donor. ${ }^{1}$

Photocurrents have also been measured in aqueous solutions containing DHP-vesicleincorporated $\mathrm{CdS}$ particles in the presence of methylviologen and glucose as a sacrificial electron donor (Figure 1). The ability of measuring photocurrent in microheterogeneous surfactant-vesicle solutions provided a means for the determination of Fermi levels at the surface of semiconductor particles. As expected, the flat-band potential varied significantly from preparation to preparation. Organized surfactant assemblies, thus, provided a convenient means for fine tuning semiconductor energy levels. ${ }^{3}$ 


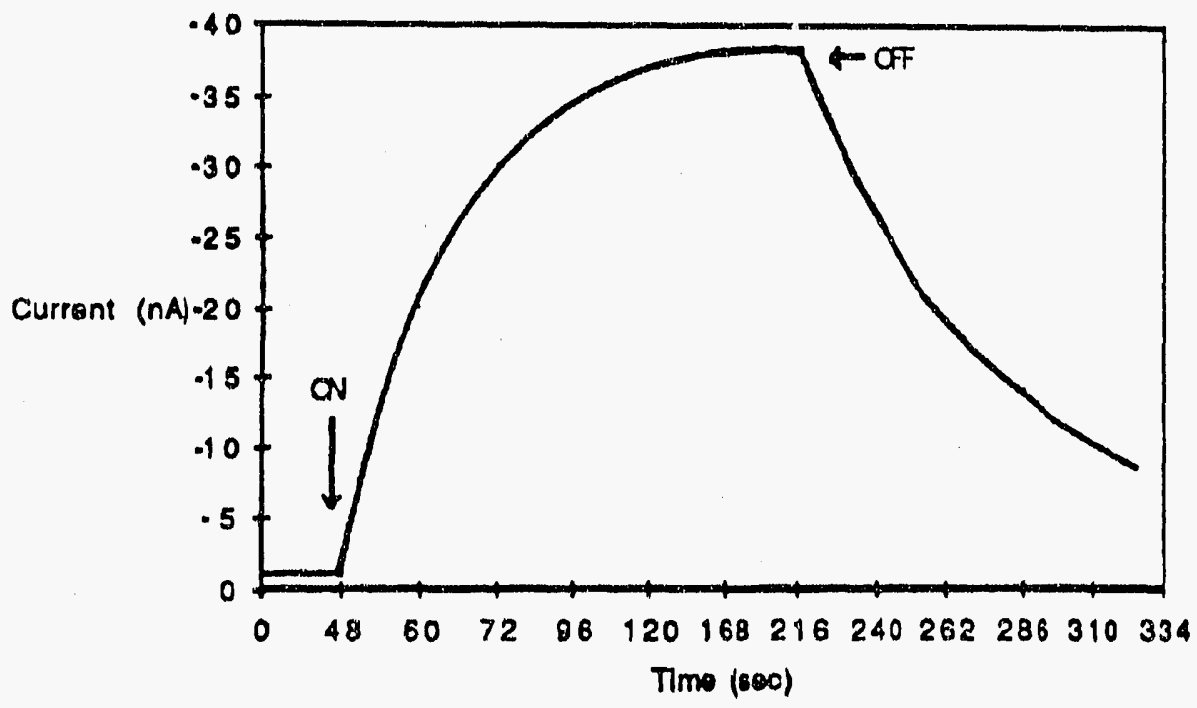

Figure 1. Plot of photocurrent against irradiation time of a $2.0 \mathrm{~mL}$ solution of DHP- $(2.0 \mathrm{mM})$ vesicle-incorporated $\operatorname{CdS}(0.2 \mathrm{mM})$ particles containing $1.0 \mathrm{mM}$ glucose and $1.0 \mathrm{mM} \mathrm{MV}^{2+}$ at $\mathrm{pH}=10$. Arrows indicate the turning on and turning off of the $450 \mathrm{~W}$ Xenon lamp used for the irradiation ( $400 \mathrm{~nm}$ cut off and water filters). The lamp delivered $\$ .0 \mathrm{~W} / \mathrm{cm}^{2}$ radiant energy.

Methodologies have been developed for the in situ formation of cadmium, lead, indium, and zinc selenide particles on the surfaces of negatively charged DHP and positively charged dioctadecyldimethylammonium bromide (DODAB) vesicles. Two different chemical approaches have been taken. In the first method, the metal-selenide particles were generated from the metal-ion-coated vesicles by exposure to gaseous hydrogen selenide. In the second method, metal-selenide particles were formed by the chemical reduction of $\mathrm{SeO}_{2}$ and $\mathrm{M}^{2+}$ in the presence of vesicles. Photoelectron transfer to methylviologen has been demonstrated for DODAB vesicles containing cadmium-selenide particles in the presence of sacrificial electron donors. ${ }^{6}$ 


\section{B. Semiconductor Particles in Bilayer Lipid Membranes}

Considerable progress has been made in the characterization of BLM-supported semiconductor and mixed-semiconductor particles and semiconductor junctions. Separation of two aqueous solutions by the BLM has allowed the convenient measurement of electrical and electrochemical properties by using macroscopic electrodes. Simultaneous electrical and spectroscopic monitoring of semiconductor particle formation on the BLM surface, as well as photoelectron transfer therein, afforded unprecedented fundamental insights.

Injection of an appropriate metal-ion precursor into one side (cis side) and hydrogen sulfide into the other side (trans side) of aqueous solutions bathing the opposites sides of a BLM has been shown to lead to the formation of cadmium, lead, zinc, mercury, and indium sulfide semiconductor particulate films. Depending on the concentration of $\mathrm{H}_{2} \mathrm{~S}$ and its infusion time, semiconductor particles of different thicknesses could be formed on the BLM surface. The proposed porous semiconductor particulate film formation and the arrangement of the working $\left(\mathrm{E}_{\mathrm{W}}\right)$, reference $\left(\mathrm{E}_{\mathrm{R}}\right)$, and counter $\left(\mathrm{E}_{\mathrm{c}}\right)$ electrodes are illustrated schematically in Figure 2. Experimental conditions have been developed for the formation of a single composition of semiconductor particulate films deposited on only one side of a BLM, two different compositions of semiconductor particulate films sequentially deposited on the same side of a BLM, and two different compositions of semiconductor particulate films deposited on the opposite side of a BLM (Figure 3). Electrochemical measurements established current-rectifying behavior and the presence of n-type (CdS, Zns, and $\left.\operatorname{In}_{2} \mathrm{~S}_{3}\right)$ and p-type $\left(\mathrm{Cu}_{2-(x+y)} \mathrm{S}\right)$ electrolyte-semiconductor (ES) junctions or semiconductor-semiconductor (SS') heterojunctions. Interestingly, prolonged voltammetric cycling converted the semiconductor particulate films on the BLM surfaces from n- to p-type behavior. ${ }^{5}$ 


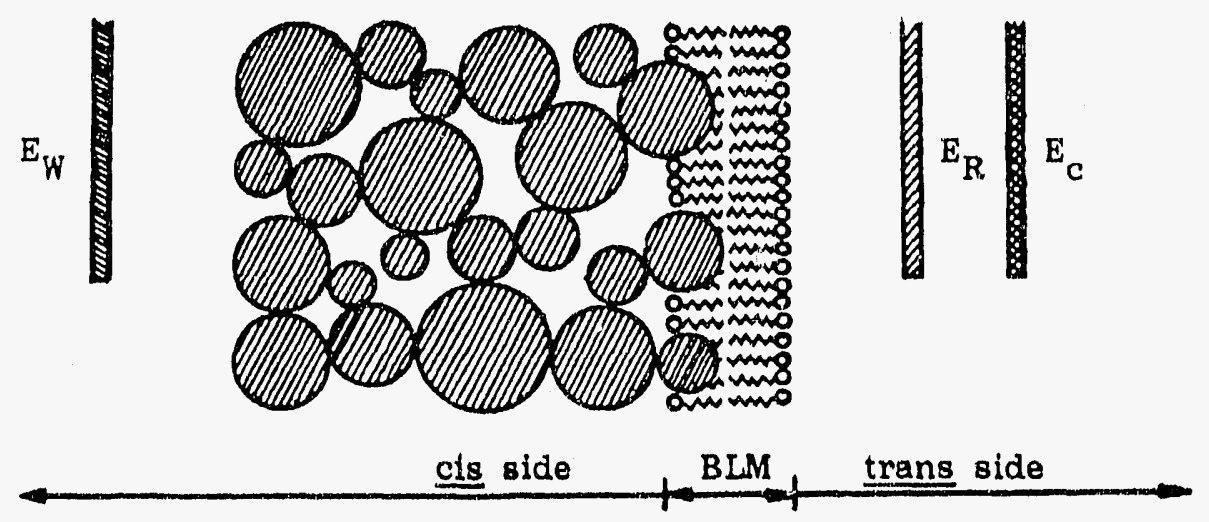

Figure 2. Schematics of the semiconductor-particulate-film-coated BLM.
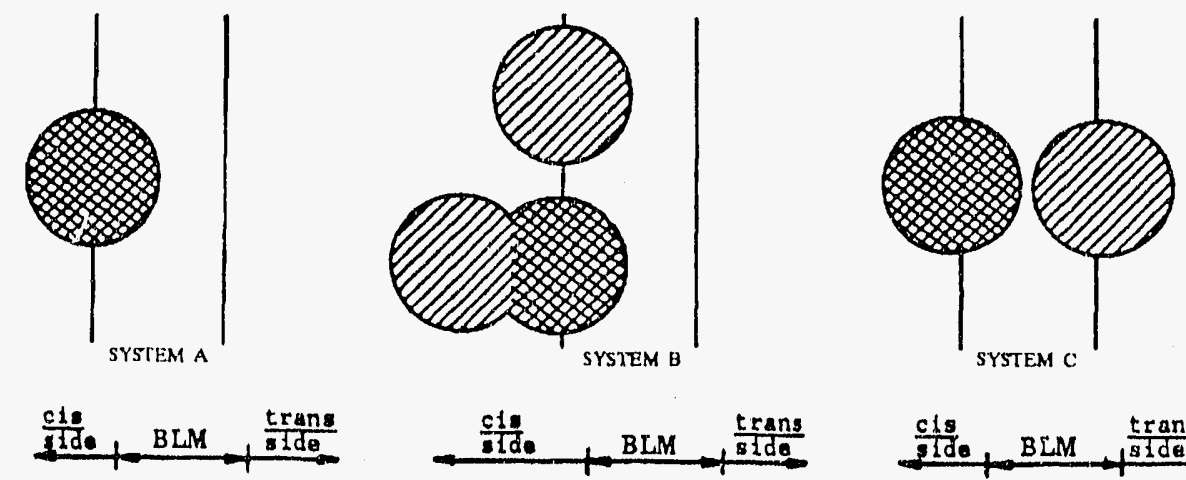

Figure 3. Schematic representation of the different semiconductor-coated BLMs. A single composition of particulate semiconductor deposited only on one side of the BLM constituted System A. Two different compositions of particulate semiconductors sequentially deposited on the same side of the BLM represent System B. Finally, two different compositions of particulates deposited on the opposite sides of the BLM made up System C.

Bandgap irradiation of a cadmium-sulfide semiconductor particulate film deposited on a glyceryl monooleate (GMO) BLM resulted in measurable photoelectric effects. The observed development of photovoltage has been rationalized in terms of generation of $\mathrm{O}_{2}{ }^{-}$ and $\mathrm{H}^{+}$in the opposite sides of the GMO BLM and that of its decay by the recombination of charges via mass transport of the ions across the BLM. ${ }^{4}$ 


\section{Semiconductor Particulate Films Formed at Monolayer Surfaces}

Perhaps the most significant accomplishment has been the development of a new versatile method for the formation of semiconductor particulate films which could be investigated both at monolayer surfaces and subsequent to their transfer onto solid supports in the solid state. The approach has been inspired by the formation of semiconductor particulate films at BLM interfaces.

Hydrogen sulfide or hydrogen selenide, introduced into an atmosphere, was allowed to infuse slowly across the compressed monolayer in contact with the aqueous metal counterion precursor of the semiconductor particulate film (Figure 4). ${ }^{8,9,11-13}$ Controlled infusion of the gas has resulted in the formation of covalent metal-sulfide or selenide bonds at a large number of sites at the compressed monolayer interface. The nascent metal sulfide microclusters grew laterally to linked, 30-50 $\AA$ diameter, $10-30 \AA$ thick polyparticulates. With continued infusion of $\mathrm{H}_{2} \mathrm{~S}$ or $\mathrm{H}_{2} \mathrm{Se}$, these polyparticles formed an interconnected semiconductor particulate film whose thickness grew to several hundred angstroms (Figure 5). The growth of the semiconductor particulate films has been monitored by reflectivity measurements in the film balance. The semiconductor particulate films, at any stage of their growth, could be quantitatively transferred to a solid support. Absorption and emission spectroscopy, electron microscopy, X-ray diffraction, scanning tunneling microscopy, and scanning tunneling spectroscopy have been used for the characterization of semiconductor particulate films. Importantly, evidence has been obtained for size quantization and dimensionality reduction. Furthermore, photoelectron transfer has been shown to be dependent on the sizes of the semiconductor particles.

Incorporation of size-quantized semiconductor particles between the hydrophilic headgroups of Langmuir-Blodgett films has also been demonstrated. 


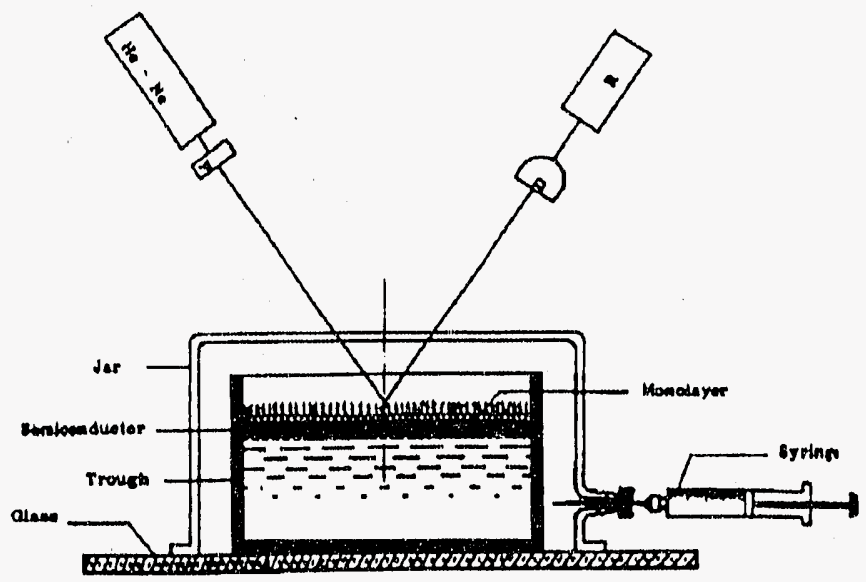

Figure 4. Schematics of the experimental arrangements used for the generatin of semiconductor particles at the negatively charged, surfactant headgroup-aqueous $\left(1.0 \times 10^{-3} \mathrm{M} \mathrm{MCl}_{2}\right)$ subphase interface and that used for the in situ monitoring of reflectivities: $P$, polarizer; $D$, detector; $R$, chart recorder.

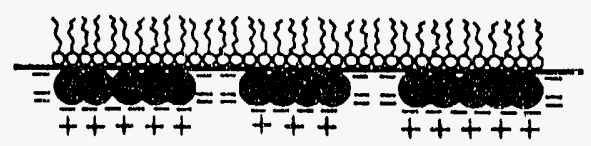

a

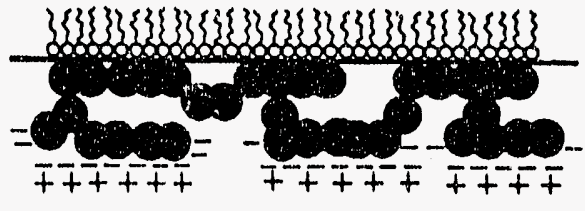

b

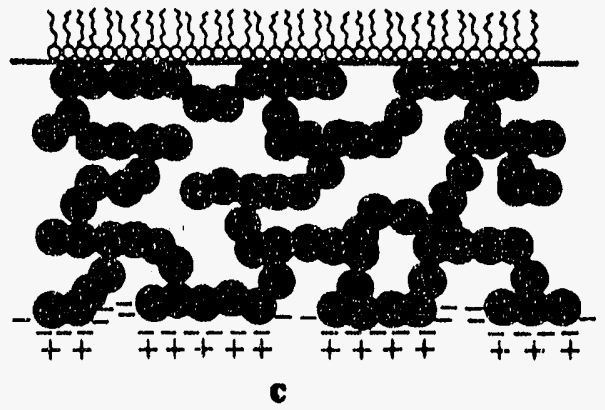

Figure 5. Proposed schematics for the initial (a) and subsequent (b and c) growth of a monolayer-supported, porous, semiconductor particulate film.

More details on these studies are provided in the publications appended to this Performance Report. 


\section{SCIENTIFIC PERSONNEL}

Dr. Janos H. Fendler

Principal Investigator

Dr. Subhash Baral

Research Assistant Professor

Dr. David Yogev

Postdoctoral Associate

Dr. Ottó Horváth

Postdoctoral Associate

Mrs. Kyunghee C. Yi

Graduate Student

Ms. Christine Dolan

Graduate Student

Mr. Jianping Yang

Graduate Student 


\section{PUBLICATIONS}

Dihexadecyl Phosphate, Vesicle-Stabilized and In-Situ-Generated Mixed CdS and ZnS Semiconductor Particles. Preparation and Utilization for Photosensitized Charge Separation and Hydrogen Generation, H.-C. Youn, S. Baral, and J. H. Fendler, J. Phys. Chem., 92, 6320-6327 (1988) (DOE/ER/13506--17).

Photoinduced Electron Transfers in Membrane Mimetic Systems, S. Baral and J. H. Fendler, in "Photoinduced Electron Transfer," Edited by M. Chanon and M. A. Fox, Elsevier Science Publishers, Amsterdam, The Netherlands, 1988, Part B, pp 541-598 (DOE/ER/13506--18).

Semiconductor Particle Mediated Photoelectron Transfers in Bilayer Lipid Membranes, S. Baral and J. H. Fendler, in "Photochemical Solar Energy Conversion", Edited by J. Norris and D. Meisel, Elsevier, New York, 1989, pp. 148-160 (DOE/ER/13506--19).

Electrochemical Investigation of Dihexadecyl Phosphate-Vesicle-Incorporated Colloidal CdS Particles, A.-C. Chang and J. H. Fendler, J. Phys. Chem., 23, 2538-2542 (1989) (DOE/ER/13506--20).

Cadmium-Sulfide-Mediated Photoelectric Effects in Bilayer Lipid Membranes, S. Baral and

J. H. Fendler, J. Am. Chem. Soc., 111, 1604-1614 (1989) (DOE/ER/13506--21). 
Bilayer Lipid Membrane Semiconductor Junctions, Spectroscopic and Electrochemical Characterizations and Photoelectron Transfer, J. H. Fendler, J. Macromol. Sci.-Chem., A27(9-11), 1167 (1990) (DOE/ER/13506--23).

Electrochemical Characterization of Bilayer Lipid Membrane Semiconductor Junctions, X. K. Zhao, S. Baral, and J. H. Fendler, J. Phys. Chem., 94, 2043-2052 (1990) (DOE/ER/13506--28).

Preparation and Characterization of Selenide Semiconductor Particles in Surfactant Vesicles, A.-C. Chang, W. F. Pfeiffer, B. Guillaume, S. Baral, and J. H. Fendler, J. Phys. Chem., 94, 4284-4289 (1990) (DOE/ER/13506--29).

Ultrasmall Semiconductor Particles Sandwiched Between Surfactant Headgroups in Langmuir-Blodgett Films, S. Xu, X. K. Zhao, and J. H. Fendler, Advanced Materials, 2, 183185 (1990) (DOE/ER/13506--30).

Template-Directed Semiconductor Size Quantization at Monolayer-Water Interfaces and Between the Headgroups of Langmuir-Blodgett Films, K. C. Yi and J. H. Fendler, Langmuir, $\underline{6}, 1519-1521$ (1990) (DOE/ER/13506--31).

Size-Quantized Semiconductor Particles Formed at Monolayer Surfaces, X. K. Zhao, Y. Yuan, and J. H. Fendler, J. Chem. Soc. Chem. Commun., 1248-1252 (1990) (DOE/ER/13506--32). 
In Situ Imaging of CdS and ZnS Semiconductor Particles in Surfactant Vesicles, B. R. Heywood, J. H. Fendler, and S. Mann, J. Coll. Interf. Sci., 138, 295-298 (1990) (DOE/ER/13506--33).

Membrane Mimetic Chemistry, J. H. Fendler, 1989 McGraw-Hill Encyclopedia of Science and Technology (1990) (DOE/ER/13506--38).

Semiconductor Particulate Films on Solid Supports, X. K. Zhao and J. H. Fendler, Chemistry of Materials, 3(1), 168-174 (1991) (DOE/ER/13506--39).

Size Quantization in Semiconductor Particulate Films, X. K. Zhao and J. H. Fendler, J. Phys. Chem., 95, 3716-3723 (1991) (DOE/ER/13506--40).

Electrical and Photoelectrochemical Characterization of CdS Particulate Films by Scanning Electrochemical Microscopy, Scanning Tunneling Microscopy and Scanning Tunneling Spectroscopy, X. K. Zhao, L. D. McCormick, and J. H. Fendler, Chemistry of Materials, in press (1991)

Electrochemical Quartz Crystal Microbalance Monitoring of Cadmium Sulfide Generation in Polypyrrole and Polypyrrole Poly(styrenesulfonate) Thin Films, M. Hepel, E. Seymour, D. Yogev, and J. H. Fendler, submitted to Chemistry of Materials (1991).

Size-Quantized Particles at Artificial Membrane Interfaces, J. H. Fendler, "Proceedings of the Workshop on the Design and Processing of Materials by Biomimicking", in press (1991). 


\section{ORAL PRESENTATIONS}

$\begin{array}{lll}\text { Year Date } & \text { Place }\end{array}$

1989 June 12-15 Thirteenth Department of

Energy Solar Photochemistry

Research Conference

Silver Creek, Colorado

1989 July $23-28$

1989

1989

1990

1990

1990
June 4-10

August

20-24

Octo

November 6-9

May 6-11

177th Meeting of the Electrochemical Society Montreal, Quebec, Canada

Fourteenth Department of Research Conference Lake Harmony, Pennsylvania

1990 International Congress on Membranes and Membrane Processes

Chicago, Illinois Energy Solar Photochemistry
Photochemical Solar Energy Conversion Utilizing Semiconductors Localized in Membrane Mimetic Systems (DOE/ER/13506--24)

Bimolecular Thick Membranes as Supports for Semiconductors and Magnetic Particles: Characterization, Utilization, and Potential

(DOE/ER/13506--25)

Size-Quantized Particles in Organized Assemblies

Bilayer Lipid MembraneSupported Electronic Devices (DOE/ER/13506--26)

Bilayer Lipid MembraneSupported Electronic Devices (DOE/ER/13506--34)

Size-Quantized Semiconductor Particles Formed at Monolayer Surfaces (DOE/ER/13506--35)

Surface Modified Bilayer Ultrathin Membranes (DOE/ER/13506--36) 
1990

August

26-31

1990

October 2

1990

1990

1990

1990

1990

1990

1990

1990 200th National Meeting of the

American Chemical Society,

Symposium of Past Kendall

Laureates

Washington, D.C.

Department of Chemical

Engineering, Pennsylvania

State University

University Park, Pennsylvania

October 15 Institute of Biophysics

Semmelweis Medical University

Budapest, Hungary

October 18 Hungarian Academy of Science

Budapest, Hungary

October 19 ELTE, Department of Colloid

Science

Budapest, Hungary

October 22 JATE, Department of Colloid Chemistry

Szeged, Hungary

October $24 \quad$ Academy of Szeged

Szeged, Hungary

October 25 Lajos Kossuth University

Debrecen, Hungary

October 26 Institute of Biophysics,

Biological Research Center

Hungarian Academy of Sciences

Szeged, Hungary

November 6
Dow Lecture Series

Bucknell University

Lewisburg, Pennsylvania
Silver and Semiconductor Particle Formation at Monolayer Interfaces (DOE/ER/13506--41)

Membrane Mimetic Chemistry

Bilayer Lipid Membrane

Supported Electronic Devices

Artificial Photosynthesis in Surfactant Vesicles - Physical Chemistry of Membrane Models

Generation of Nanósized TwoDimensional Particles at Monolayer Interffaces

Interactions and Reactions in Reversed Micelles

Preparation of Size-Quantized Semiconductor and Magnetic Particles in Model Membranes

Preparation and Characterization of Polymerized Surfactant Aggregates

Mechanisms of Membrane Fusion Membrane Mimetic Chemistry 
Year Date Place Title

\begin{tabular}{|c|c|c|c|}
\hline 1991 & March 5 & $\begin{array}{l}\text { La Societe Royale de Chimie } \\
\text { Lecture, University of Namur, } \\
\text { Belgium }\end{array}$ & $\begin{array}{l}\text { Size-Quantized Silver and } \\
\text { Semiconductor Particulate Films }\end{array}$ \\
\hline 1991 & April 2-4 & $\begin{array}{l}\text { Workshop on the Design and } \\
\text { Processing of Materials by } \\
\text { Biomimicking, Seattle, WA }\end{array}$ & $\begin{array}{l}\text { Size-Quantized Particles at } \\
\text { Artificial Membrane Interfaces } \\
\text { (DOE/ER/13506--42) }\end{array}$ \\
\hline 1991 & May 5-10 & $\begin{array}{l}\text { 179th Electrochemical Society } \\
\text { Meeting, Washington, DC }\end{array}$ & $\begin{array}{l}\text { Photoelectron Transfer at Size- } \\
\text { Quantized Semiconductor Particles } \\
\text { (DOE/ER/13506--43) }\end{array}$ \\
\hline 1991 & June 2-6 & $\begin{array}{l}\text { Fifteenth Department of Energy } \\
\text { Solar Photochemistry Research } \\
\text { Conference, Snowmass, Colorado }\end{array}$ & $\begin{array}{l}\text { Photochemical Solar Energy } \\
\text { Conversion Utilizing } \\
\text { Semiconductors Localized in } \\
\text { Membrane Mimetic Systems } \\
\text { (DOE/ER/13506--44) }\end{array}$ \\
\hline 991 & July $7-13$ & $\begin{array}{l}\text { 7th International Conference } \\
\text { on Surface and Colloid Science } \\
\text { Compiègne, France }\end{array}$ & $\begin{array}{l}\text { Scanning Tunneling Microscopic, } \\
\text { Optical, and Scanning Tunneling } \\
\text { Spectroscopic Characterization } \\
\text { of Size-Quantized Cadmium } \\
\text { Selenide Particulate Films In } \\
\text { Situ Generated at Monolayer } \\
\text { Interfaces (DOE/ER/13506--45) }\end{array}$ \\
\hline
\end{tabular}

VI. STATEMENT OF REMAINING FUNDS

All funds from this grant will be spent by the end of the project period (March 31, 1992). 
1 